\title{
Twelfth mode on-demand band notch UWB antenna for underlay cognitive radio
}

\author{
Laith Wajeeh Abdullah ${ }^{1}$, Musa H. Wali ${ }^{2}$, Adheed H. Saloomi ${ }^{3}$ \\ ${ }^{1,3}$ Department of Electrical Engineering, Mustansiriyah University, Iraq \\ ${ }^{2}$ Electronics and Communication Department, University of Qadisiyah, Iraq \\ ${ }^{1}$ Communication Techniques Engineering Department, Al-Furat Al-Awsat Technical University, Iraq
}

\begin{tabular}{l} 
Article Info \\
\hline Article history: \\
Received Jan 1, 2021 \\
Revised Mar 18, 2021 \\
Accepted Mar 20, 2021 \\
\hline
\end{tabular}

\section{Keywords:}

Band notch

Cognitive radio

PIN diode

Reconfigurable antenna

Ultra-wideband

\begin{abstract}
A wide-slot ultra-wideband (UWB) antenna with on-demand band rejection characteristics that can serve underlay cognitive radio is presented in this paper. This antenna is designed to work in twelve operation modes; one to cover the whole UWB while each of the rest modes excludes one or more of the ranges that are allocated for Worldwide Interoperability for Microwave Access (WiMax), C-band, wireless local area network (WLAN), X-band and International Telecommunication Union (ITU) in a single, dual, triple, quad or penta band rejection state. A spiral shape slot in the patch and three slots mainly based on half-circular structures in the ground plane are the means to create the desired frequency notches. A positive-intrinsic-negative (PIN) diode across each of these slots is used to enable/disable band(s) rejection process. Configuration of the proposed antenna to the desired mode of operation is decided by the state of its four PIN diodes. This work is simulated by computer simulation technology (CST) v.10. It's S11, voltagestanding-wave-ratio (VSWR) and realized gain results when combined with antenna's $25 \times 25 \times 0.8 \mathrm{~mm}^{3}$ compact size and the large number of modes and states, all ensure its capability to eliminate or reduce the interference within the targeted bands and hence being suitable for the applications of underlay cognitive radio.
\end{abstract}

This is an open access article under the CC BY-SA license.

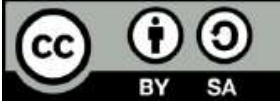

\section{Corresponding Author:}

Laith Wajeeh Abdullah

Communication Techniques Engineering Department

Al-Furat Al-Awsat Technical University,

Najaf, Iraq

Email: coj.lat@atu.edu.iq

\section{INTRODUCTION}

Merits like low power consumption, wide impedance bandwidth, constant gain, jamming immunity and higher capacity [1] combined with the wide range of applications including imaging systems, target localization and automotive applications [2], [3] lead ultra-wideband (UWB) systems to pick an increasing interest in the world of wireless communications since its declaration by Federal Communications Commission (FCC) in 2002 [4]. Unfortunately, many wireless technologies are coexist within the range 3.1$10.6 \mathrm{GHz}$ that is allocated for UWB. Worldwide Interoperability for Microwave Access (WiMax), C-band, wireless local area network (WLAN), X-band and International Telecommunication Union (ITU) technologies summarized in Table 1 all may interfere with UWB systems [5], [6]. Antennas with bandrejection characteristics are the basic mean to cancel or to reduce the effect of this interference which is crucial for some applications. 
Band rejection can be fixed that certain band(s) within the UWB spectrum can be permanently excluded under interference presence or absence. Many antennas have been designed to overcome interference defects within specific bands. WLAN is rejected via a C-shape parasitic element of the antenna in [7]. Dual band rejection is implemented in [8] and [9]. A U-shape slot on the radiator and an L-shape slit on ground plane of [8] bans WiMax/WLAN frequencies, whilst WLAN/X-band ranges are prohibited by a pair of parasitic elements in the wide slot of the antenna in [9]. On the other hand, [10], [11] presents triple band-notched systems. Patchs and partial grounds of these systems have been implemented with a variety of $\mathrm{C}$-shape and U- shape slots that deny the radiation within WiMax/WLAN/X-band regions.

Table 1. Frequency band allocation

\begin{tabular}{ll}
\hline \multicolumn{1}{c}{ Band } & \multicolumn{1}{c}{ Range $(\mathrm{GHz})$} \\
\hline WiMax & $3.3-3.6$ \\
WLAN & $5.15-5.825$ \\
C-band & $3.7-4.2$ \\
X-band & $7.25-7.75$ \\
ITU & $8.02-8.4$ \\
\hline
\end{tabular}

Contrast to fixed band-notched systems that have only a single operation mode that reject specific band/bands and doesn't cover the whole UWB, reconfigurable antennas for underlay cognitive radio that can operate at least into two modes, exclude certain bands on demand, and covering the UWB are more desirable and suitable. Antennas in this approach are usually modified UWB antennas that can be configured to a particular mode of operation using switching elements like positive-intrinsic-negative (PIN) diodes [12]. The slot antennas of [1] and [13] can be configured as UWB antennas or to reject WLAN band within the UWB range. This depends on the ON/OFF state of the PIN diode within the U-shape slot in the feed line of [1] and the triangular-shape slot in the patch of [13]. Two PIN diodes are used in [2] and [14] to configure the antenna in an UWB mode or WiMax/WLAN rejection modes. These two diodes are used across the feed-line U-shape and line-shape slit of the patch in [2], while they link the L-shape radiator stub and L-shape ground slit in [14].

This paper presents a reconfigurable UWB wide slot antenna for underlay cognitive radio applications. This antenna with on demand band-notched characteristics is designed to work in twelve modes including the UWB plus eleven modes in single, dual, triple, quad and penta band rejection states. Starting by the UWB antenna design, both radiator and ground plane of a circular patch wide slot antenna are modified to cover the 3.1-10.6 GHz range. Then, spiral slot on the patch, connected-arcs slot below the feed line and two wave slots in the bottom of the ground plane are used to create the band-notched characteristics in WiMax/C-band/WLAN/X-band/ITU regions. Four PIN diodes across these slots are used to configure the antenna in the desired mode of operation. To our best knowledge, the antenna in this paper provides a large number of operation modes combined with an efficient use of the available states result from the switching elements. This compact antenna has twelve operation modes with various band rejection options out of the available sixteen states provided by its four switches. CST studio suite is used to simulate this work. Input reflection coefficient, gain and voltage-standing-wave-ratio (VSWR) results are presented which all confirm the feasibility of the proposed antenna.

\section{ANTENNA DESIGN}

The antenna in this work is built on an area of $25 \times 25 \mathrm{~mm}^{2}$ of a Rogers RT/Duroid 5880 substrate of $0.8 \mathrm{~mm}$ height. This two sided metalized substrate has relative permittivity of 2.3 and tangential loss of 0.0009. Its optimized dimensions are given in Table 2 while the geometry of this antenna is shown in Figure 1. Design procedure is mainly carried out through three steps; the first is to design an antenna that covers the UWB spectrum, next is to create the structures that are responsible to notch targeted bands and finally how to reconfigure this antenna in the demanded operation mode.

Table 2. Optimum dimensions (in $\mathrm{mm}$ )

\begin{tabular}{|c|c|c|c|c|c|c|c|c|c|c|c|c|c|c|c|}
\hline \multicolumn{2}{|c|}{ Substrate } & \multicolumn{2}{|c|}{ Patch } & \multicolumn{2}{|c|}{ Feed line } & \multicolumn{2}{|c|}{ Ground Plane } & \multicolumn{2}{|c|}{ Slot1 } & \multicolumn{2}{|c|}{ Slot2 } & \multicolumn{2}{|c|}{ Slot3 } & \multicolumn{2}{|c|}{ Slot4 } \\
\hline Lsub & 25 & $\mathrm{Lp}$ & 8 & Lf1 & 2 & Lgs & 14 & L1s1 & 2 & L1s2 & 2.25 & L1s3 & 0.75 & L1s4 & 0.75 \\
\hline Wsub & 25 & $\mathrm{Wp}$ & 8 & Lf2 & 2.5 & Wgs & 19 & W1s1 & 0.5 & L2s 2 & 0.85 & W1s3 & 0.15 & W1s4 & 0.35 \\
\hline Hsub & 0.8 & $\mathrm{Rp}$ & 6.65 & Wf1 & 1.5 & R1gs & 1 & W2s1 & 0.75 & W1s2 & 0.25 & R1s3 & 0.4 & $\mathrm{R} 1 \mathrm{~s} 4$ & 0.25 \\
\hline & & & & Wf2 & 0.75 & $\mathrm{R} 2 \mathrm{~g} 2$ & 4 & $\mathrm{R} 1 \mathrm{~s} 1$ & 2.25 & $\mathrm{R} 1 \mathrm{~s} 2$ & 0.25 & & & & \\
\hline & & & & & & R3gs & 9.5 & $\mathrm{R} 2 \mathrm{~s} 1$ & 1 & $\mathrm{R} 2 \mathrm{~s} 2$ & 0.45 & & & & \\
\hline & & & & & & $\mathrm{Lgc}$ & 0.5 & $\mathrm{R} 3 \mathrm{~s} 1$ & 1.75 & $\mathrm{R} 3 \mathrm{~s} 2$ & 1.15 & & & & \\
\hline & & & & & & Wgc & 1.75 & $\mathrm{R} 4 \mathrm{~s} 1$ & 0.5 & & & & & & \\
\hline
\end{tabular}




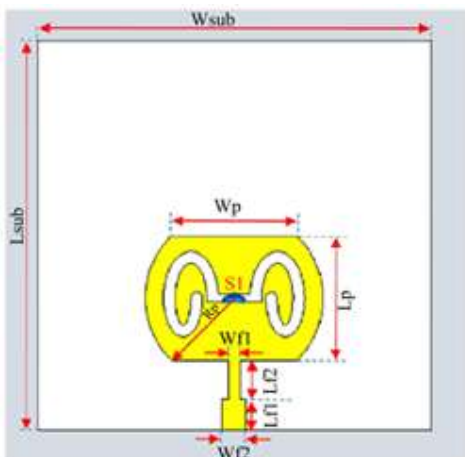

(a)

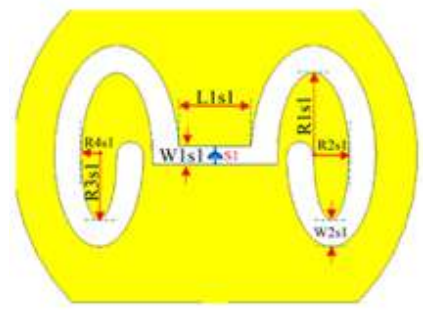

(c)

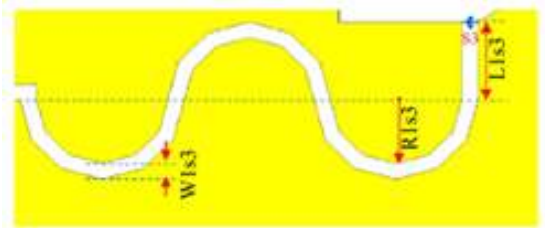

(e)

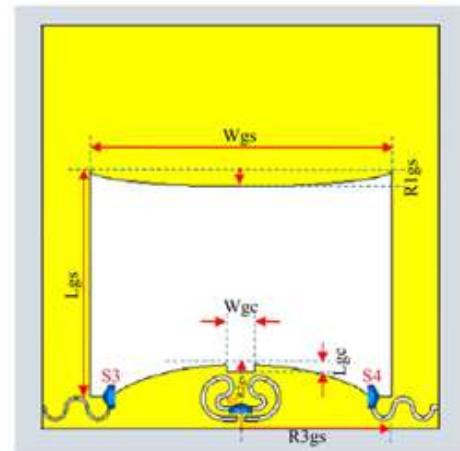

(b)

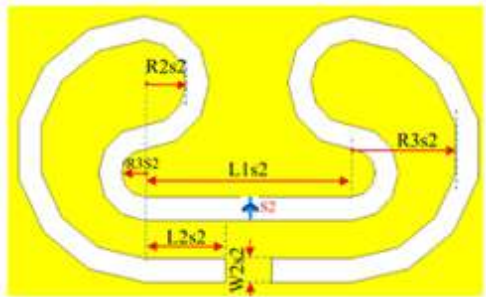

(d)

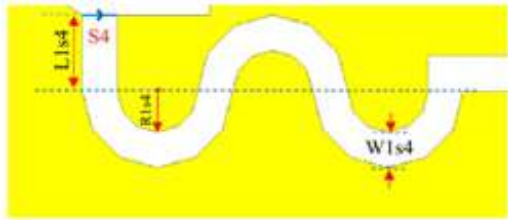

(f)

Figure 1. Geometry of the proposed antenna: (a) front view, (b) back view, (c) Slot1, (d) Slot2, (e) Slot3 and (f) Slot4

\subsection{UWB antenna}

The UWB antenna in this paper is based on a wide slot antenna with a modified circular patch and a modified rectangular slot. To enhance impedance bandwidth, upper and lower ends of the patch are trimmed whilst two half-elliptical structures are added to the top and bottom ends of the ground slot. Then, two rectangular strips are removed from feed line and small rectangle is cut from the ground plane under the feed line. The progress in the design of this UWB antenna and its influence on the input reflection coefficient are presented in Figure 2.

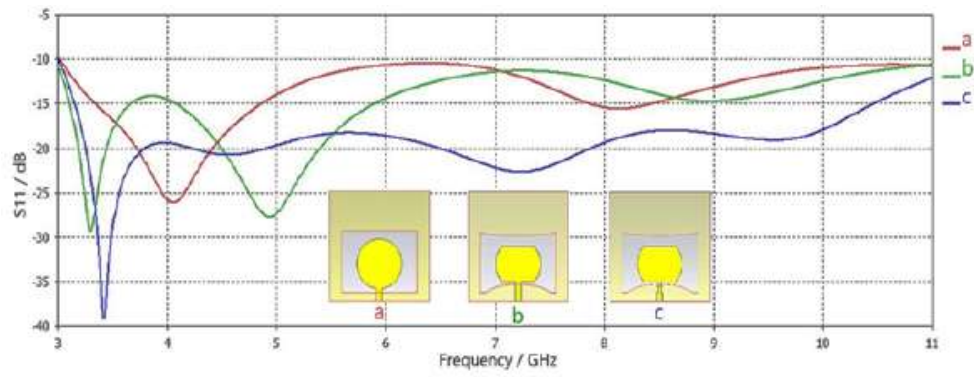

Figure 2. S11 of the UWB antenna

\subsection{Notch creation}

WLAN, X-band, ITU, WiMax, and C-band regions are the targets of band rejection in this design. Notches are created for those regions in a step-by-step procedure. At first, WLAN is omitted from the UWB 
radiation of this antenna by an etching a slot at the center of its patch. Slot1 shown in Figure 1 (c) consists of two identical spiral sections combined by a line slot. It is designed as a $\lambda_{\mathrm{g}} / 2$ slot according to (1) [15]-[17].

$$
\begin{aligned}
& L_{\text {slot }}=\frac{c}{2 f_{n} \sqrt{\varepsilon_{e}}} \\
& \varepsilon_{e} \approx \frac{\varepsilon_{r}+1}{2}
\end{aligned}
$$

Where; $L_{\text {slot }}$ : slot length , $f_{n}$ :notch frequency, c : velocity of light, $\varepsilon_{e}$ :effective permittivity, $\varepsilon_{r}$ : relative permittivity and $\lambda_{g}$ : guided wavelength.

The realization of these slots is based on (3)-(5).

$$
\begin{aligned}
& L_{\text {slot } 1} \approx P_{1}+P_{2}+L 1 s 1+W 2 s 1 \\
& P_{1}=\pi \sqrt{2 \times\left(R 1 s 1^{2}+R 2 s 1^{2}\right)-\frac{(R 1 s 1-R 2 s 2)^{2}}{2}} \\
& P_{2}=\pi \sqrt{2 \times\left(R 3 s 1^{2}+R 4 s 1^{2}\right)-\frac{(R 3 s 1-R 4 s 2)^{2}}{2}}
\end{aligned}
$$

As it can be seen in Figure 3, this slot has an impact to reject radiation within the WLAN band. This figure also presents how some slot parameters affect the response. It shows that changing the slot length mainly affects the resonance frequency while its width alters both resonance frequency and bandwidth.

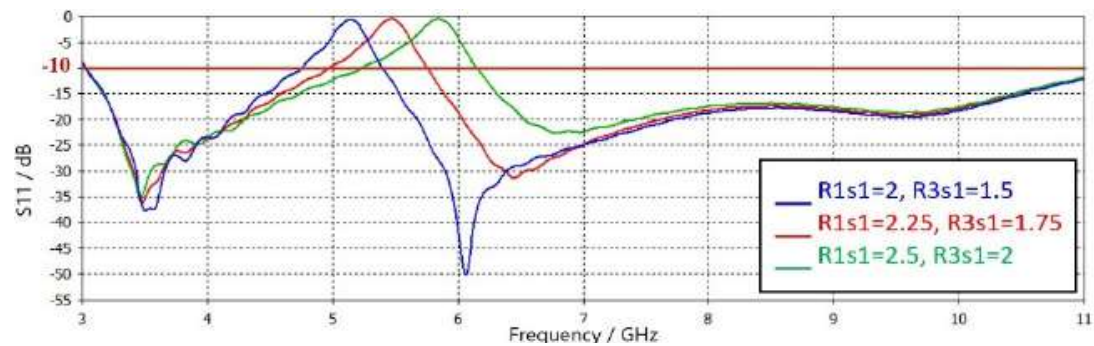

(a)

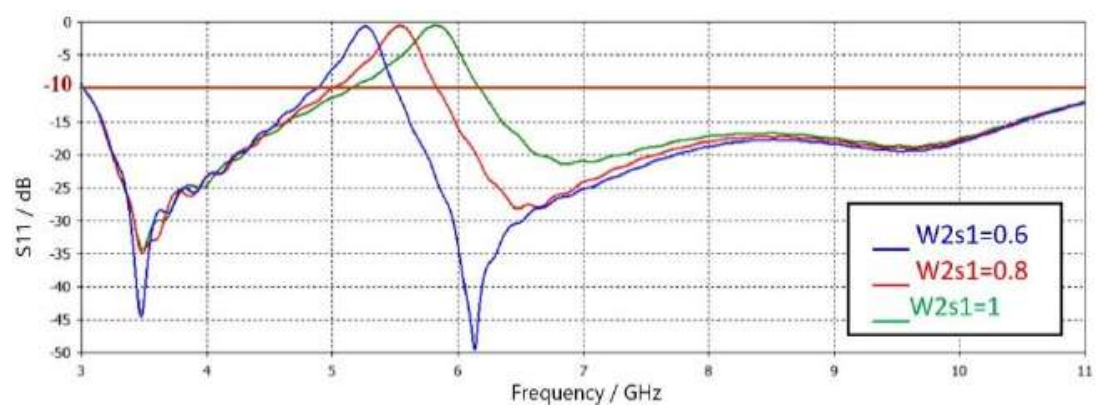

(b)

Figure 3. S11 results: (a) changing slot1 length and (b) changing slot1 width

Precluding X-band and ITU regions from the radiation of the proposed antenna is accomplished by etching a second slot at the ground plane just beneath the feed line. Slot2 illustrated in Figure 1 (d) is created as $\lambda_{\mathrm{g}} / 2$ slot. Parametric study outcomes of Figure 4 links changing slots' width and length with the bandwidth and resonance frequency. Slot2 length is implemented as (6).

$$
L_{s l o t 2} \approx 2 \pi(R 1 s 2+R 2 s 2+R 3 S 2)+L 1 s 2+2 \times L 2 S 2+W 1 s 2
$$

WiMax is rejected via a wave shape slot etched on the left bottom corner of the ground plane which was illustrated in Figure 1.e and defined as slot3. It is designed as a $\lambda_{\mathrm{g}} / 4$ slot depending (7). [17], [18]. Its length is carried out according to (8). S11 parametric study curves of this slot are presented in Figure 1 (e). It can be observed that increasing the width of this slot results in including C-band in the rejected region. So, a

Twelfth mode on-demand band notch UWB antenna for underlay cognitive radio (Laith Wajeeh Abdullah) 
similar wave slot but with different width is created on the counterpart of the ground plane as illustrated in Figure 1 (f). Creation of this slot -named slot4- which is based on (9) results in blocking the WiMax and C-band regions. S11 results are presented in Figure 5.

$$
\begin{aligned}
& L_{\text {slot }}=\frac{c}{4 f_{n} \sqrt{\varepsilon_{e}}} \\
& L_{\text {slot } 3} \approx 3 \pi R 1 s 4+L 1 s 4+W 1 s 4 \\
& L_{\text {slot } 4} \approx 3 \pi R 1 s 4+L 1 s 4+W 1 s 4
\end{aligned}
$$

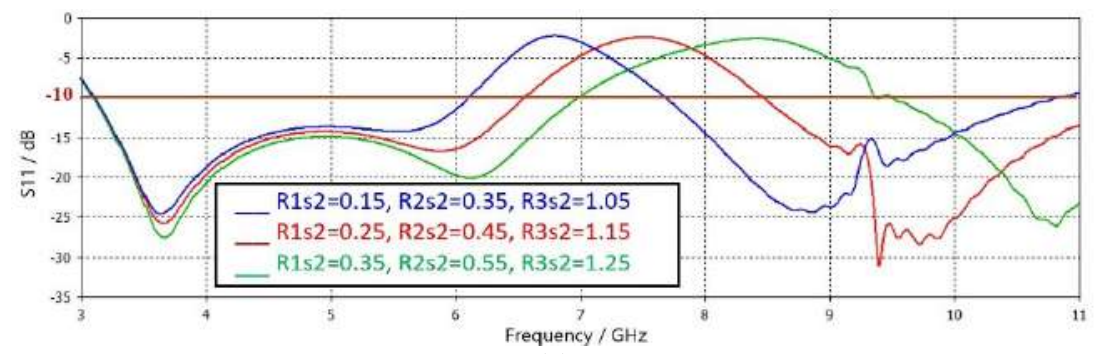

(a)

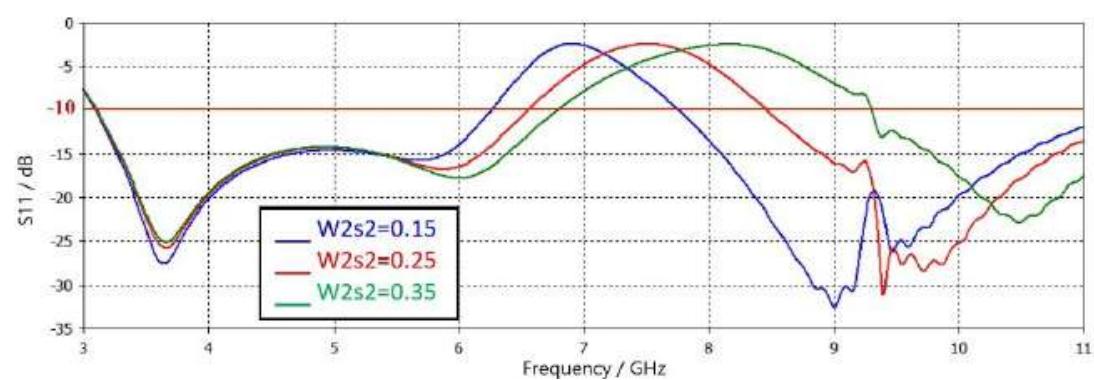

(b)

Figure 4. S11 results: (a) changing slot2 length and (b) changing slot2 width

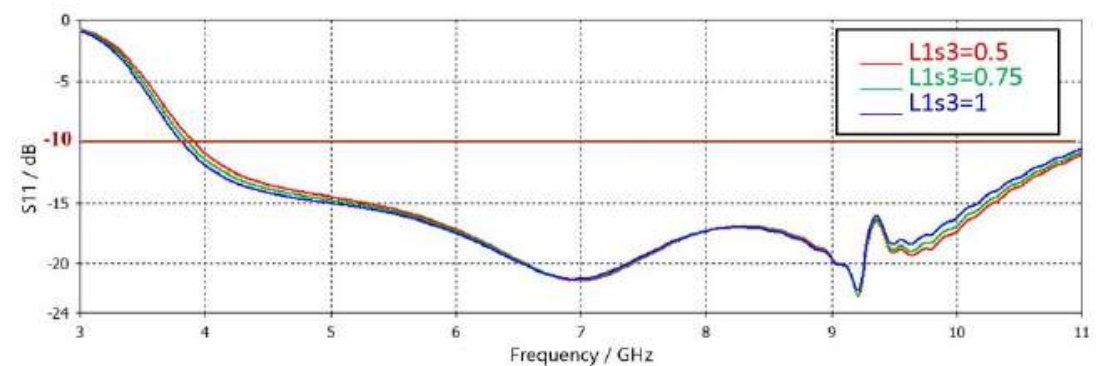

(a)

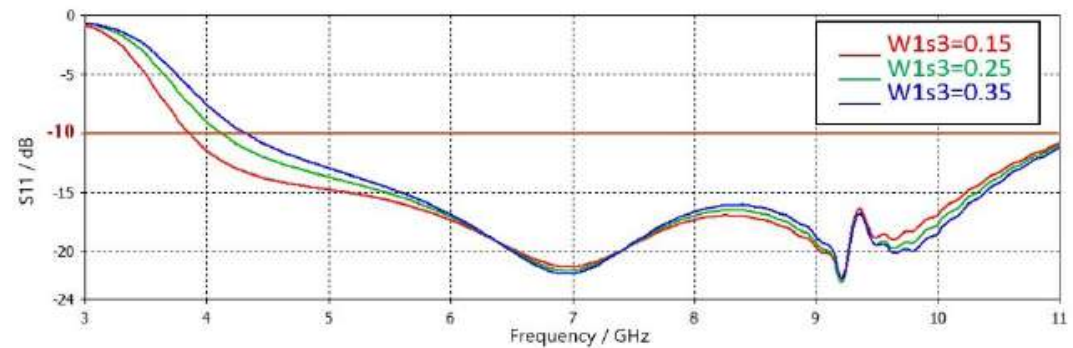

(b)

Figure 5. S11 results: (a) changing slot3 length and (b) changing slot3 width 


\subsection{Configuration}

To configure the antenna in this design, PIN diodes are used as the switching elements that select the mode of operation. Four PIN diodes are placed in the notching slots to allow/prevent band filtering process. HPND-4005 [19] is the switching element used in reconfiguration of the antenna in this paper. This PIN diode is represented in this work by its equivalent circuits for its ON/OFF states that are shown in Figure 6. The proposed design can work in UWB mode as well as another eleven band-notched modes that target WiMax, Cband, WLAN, Xband and ITU bands in various rejection states. Operation modes along with diodes' states, rejected bands and rejection states are listed in Table 3.

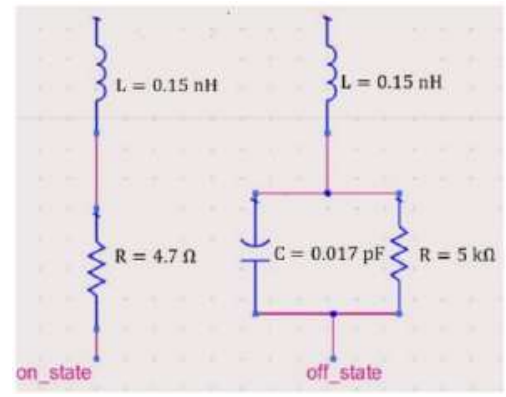

Figure 6. Equivalent circuit of HPND-4005 PIN diode

Table 3. Operation modes

\begin{tabular}{cccccll}
\hline Mode & S1 & S2 & S3 & S4 & \multicolumn{1}{c}{ Rejected bands } & Rejection state \\
\hline 1 & 1 & 1 & 1 & 1 & No band rejected (UWB) & No-band rejection \\
2 & 0 & 1 & 1 & 1 & WLAN & Single-band rejection \\
3 & 1 & 1 & 0 & 1 & WiMax & Dual-band rejection \\
4 & 0 & 1 & 0 & 1 & WiMax+WLAN & \\
5 & 1 & 0 & 1 & 1 & Xband+ITU & Triple-band rejection \\
6 & 1 & 1 & 1 & 0 & WiMax+Cband & \\
7 & 0 & 0 & 1 & 1 & WLAN+Xband+ITU & \\
8 & 1 & 0 & 0 & 1 & WiMax+Xband+ITU & Quad-band rejection \\
9 & 0 & 1 & 1 & 0 & WiMax+Cband+WLAN & \\
10 & 0 & 0 & 0 & 1 & WLAN+WiMax+Xband+ITU & \\
11 & 1 & 0 & 1 & 0 & WiMax+Cband+Xband+ITU & \\
12 & 0 & 0 & 1 & 0 & WiMax+Cband+WLAN+Xband+ITU & Penta-band rejection \\
\hline
\end{tabular}

\section{RESULTS AND DISCUSSIONS}

The antenna in this paper is designed as a frequency reconfigurable antenna that can be used for underlay cognitive radio. It can be reconfigured via the state of its four switching elements. This design is capable of covering the UWB as dictated by the results of S11 in Figure 7 (a). On the other hand the $-10 \mathrm{~dB}$ condition is not achieved for the WLAN, WiMax regions for the two curves of Figure 7 (b). Moreover S11 is greater than $-10 \mathrm{~dB}$ for each of the dual band notch modes that excludes WiMax/C-band, WiMax/WLAN and $\mathrm{X}$-band/ITU as shown in Figure 7 (c). The same condition for rejection is verified for the triple-band notch modes shown in Figure 7 (d) including WiMax/C-band/WLAN, WiMax/X-band/ITU and WLAN/Xband/ITU. The results of simulation presented of Figure 7 (e) also ensure the capability of this antenna to reject four bands into two modes including WLAN/WiMax/X-band/ITU and WiMax/C-band/X-band/ITU. Finally, disabling all switches except S3 results in the S11 curve of Figure 7 (f) which verifies the exclusion of all targeted bands within the UWB spectrum.

Current distribution can give an interpretation for notch creation in the rejected bands. In Figure 8 (a) current is focused around the $\lambda_{\mathrm{g}} / 2$ slot of the patch at $5.5 \mathrm{GHz}$ in opposite directions where $\mathrm{S} 1$ is OFF, that results in canceling the radiation at WLAN band. Turning S2 to the OFF-state results in concentrating the current around slot 2 of the ground plane at $7.5 \mathrm{GHz}$ in opposite directions as seen in Figure 9 (a) which leads to Xband/ITU dual band rejection. It can also be seen that disabling S4 gives rise to current around the slot at the bottom right corner of the ground plane as shown in Figure 10 (a) that cancels the radiation of WiMax/C-band regions. These states can be compared to their counter parts in Figure 8 (b), Figure 9 (b) and Figure 10 (b). Here, enabling the switch across the slot results in focusing current in the feed line and patch edges with minor distribution observed around the slots which leads to canceling notching effects. 


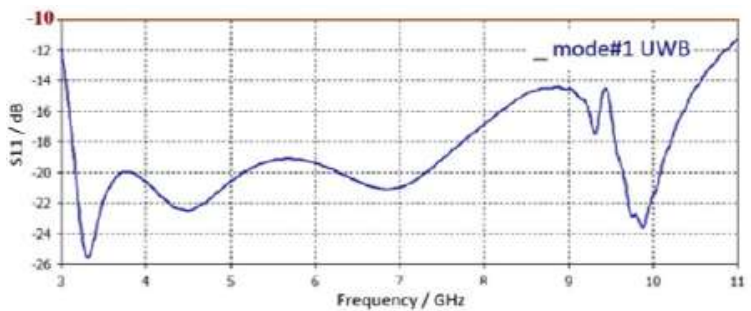

(a)

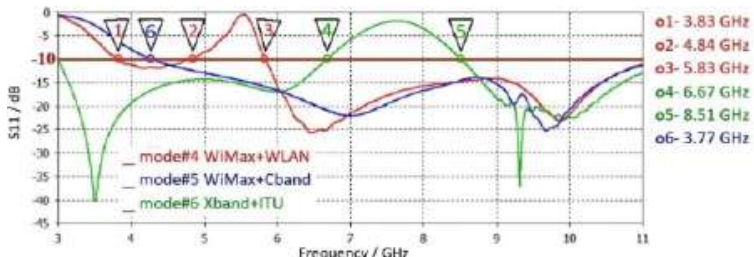

(c)

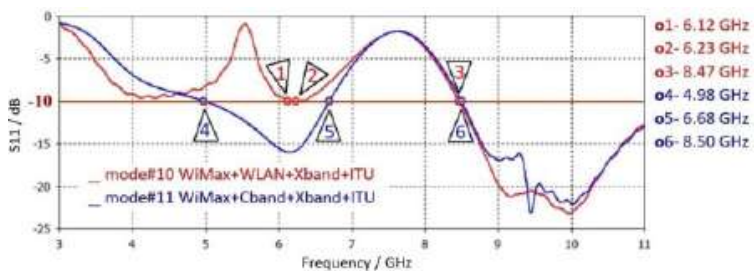

(e)

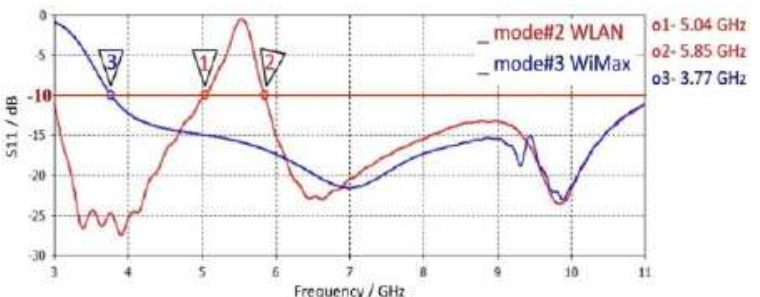

(b)

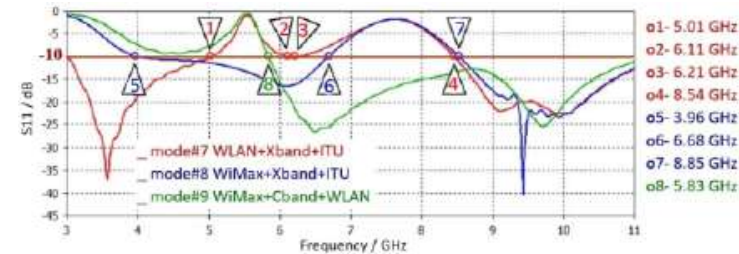

(d)

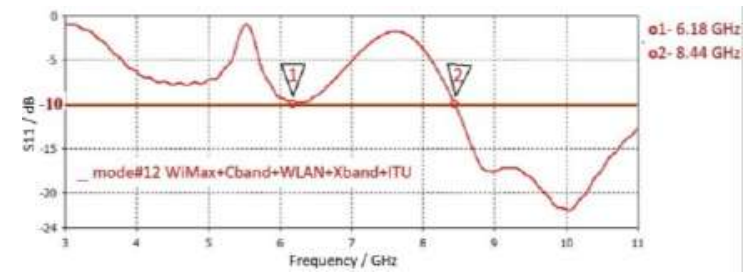

(f)

Figure 7. S11 results: (a) UWB, (b) single-band rejection, (c) dual-band rejection, (d) triple-band rejection, (e) quad-band rejection and (f) penta-band rejection

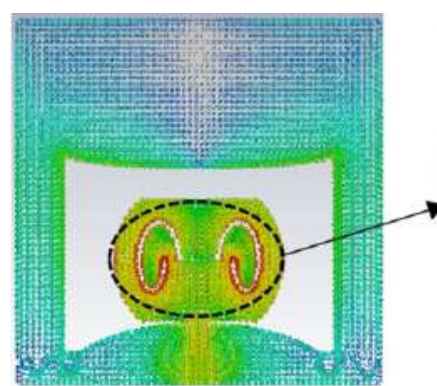

(a)

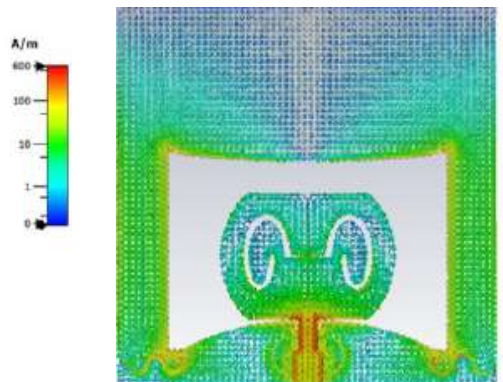

(b)

Figure 8. Surface current distribution at $5.5 \mathrm{GHz}$ when; (a) S1 OFF and (b) S1 ON

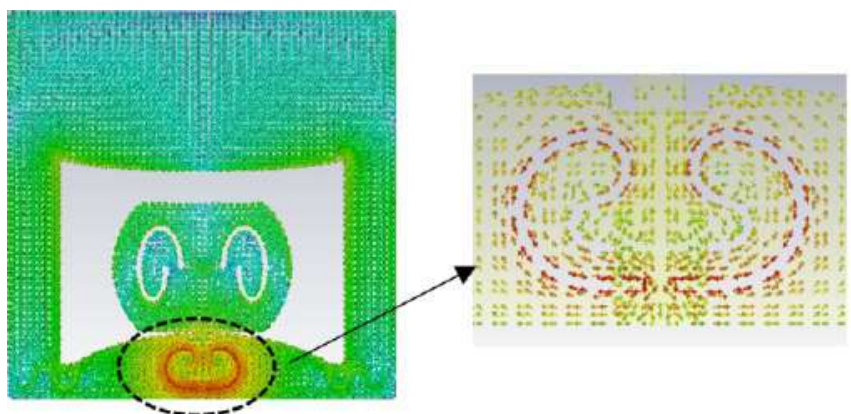

(a)

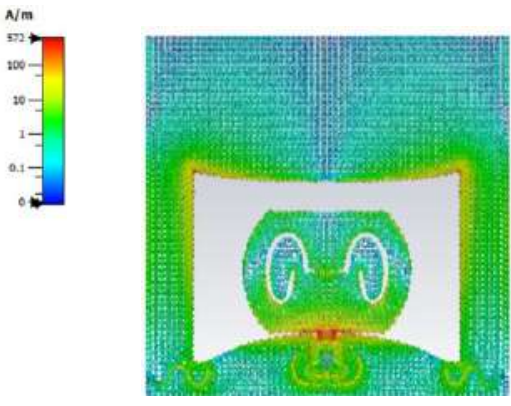

(b)

Figure 9. Surface current distribution at $7.5 \mathrm{GHz}$ when; (a) S2 OFF and (b) S2 ON 


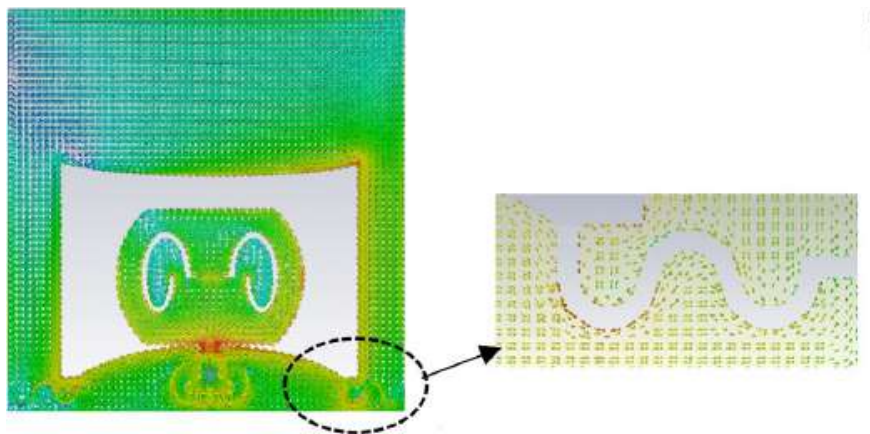

(a)

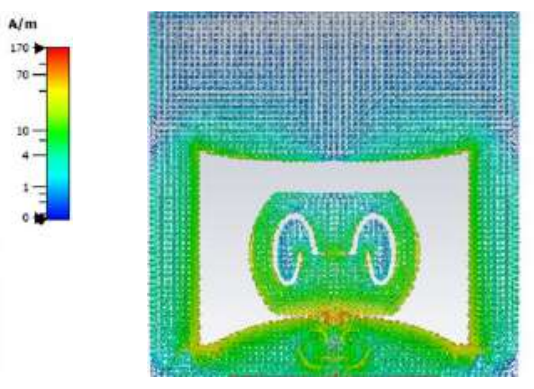

(b)

Figure 10. Surface current distribution at $3.6 \mathrm{GHz}$ when: (a) S4 OFF and (b) S4 ON

Moreover, realized gain and VSWR results are good proofs of the feasibility of the design. The antenna has a positive gain along the UWB spectrum with a maximum value around $5 \mathrm{~dB}$ as it can be seen in Figure 11 (a). On the other hand, intense decrease is observed at each of the notched bands as illustrated in Figures 11 (b) to (f). Furthermore VSWR value below 2 along the 3.1-10.6 GHz range in Figure 12 (a) is a verification of UWB radiation whilst the high values of VSWR at notched frequencies are evidences of good rejection in the interfering targeted regions as illustrated in Figures 12 (b) to (f). Finally a comparison of the proposed design with recent related works in terms of size, number of switches, number of operation modes, rejected bands, and rejection states is listed in Table 4.

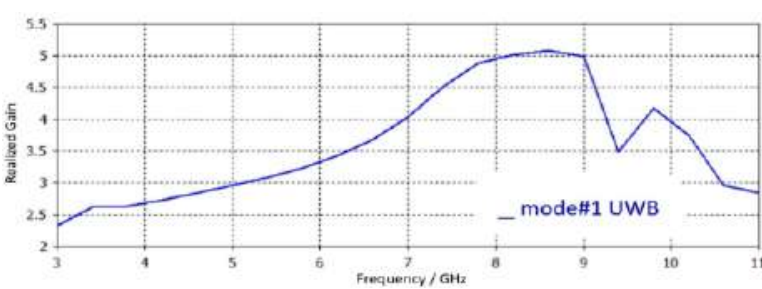

(a)

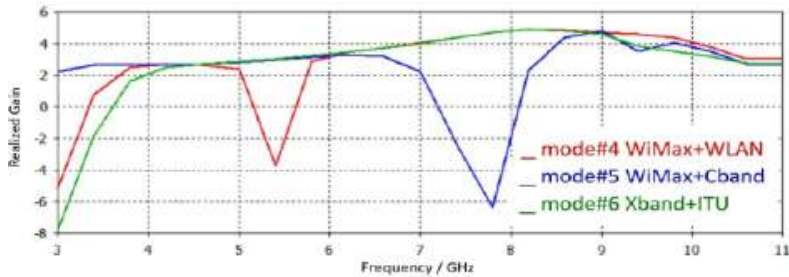

(c)

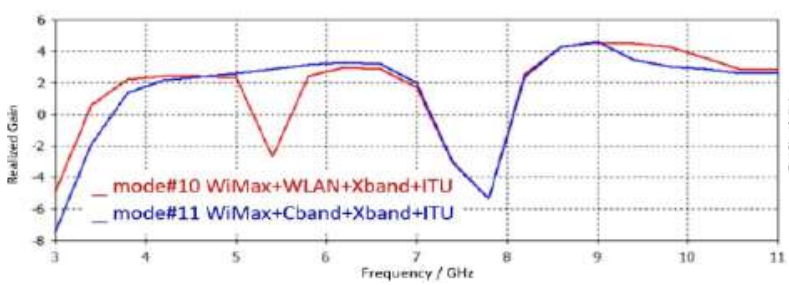

(e)

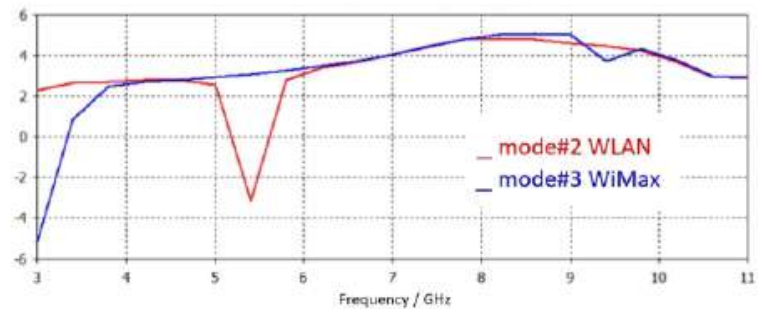

(b)

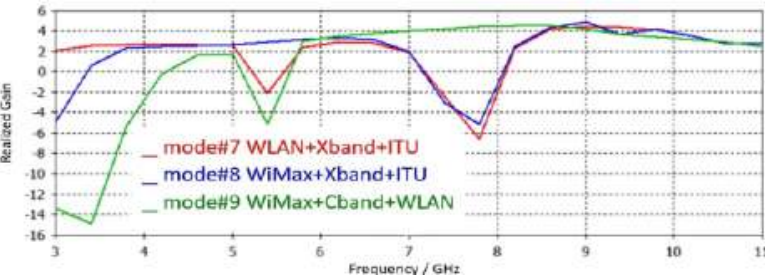

(d)

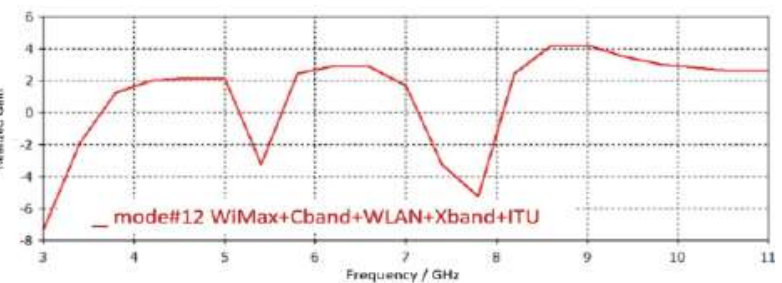

(f)

Figure 11. Realized gain: (a) UWB, (b) single-band rejection, (c) dual-band rejection, (d) triple-band rejection, (e) quad-band rejection, and (f) penta-band rejection 


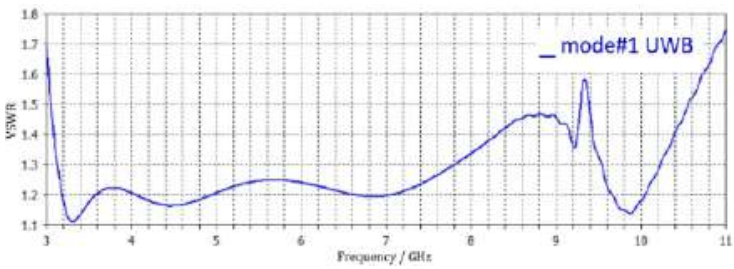

(a)

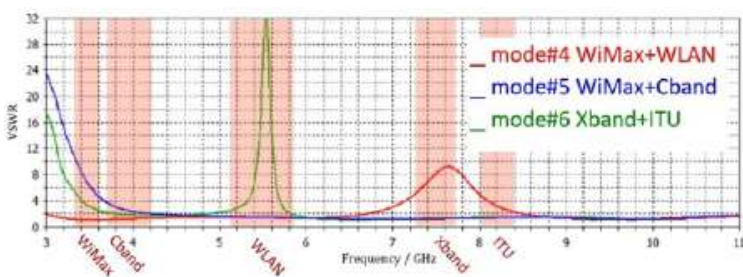

(c)

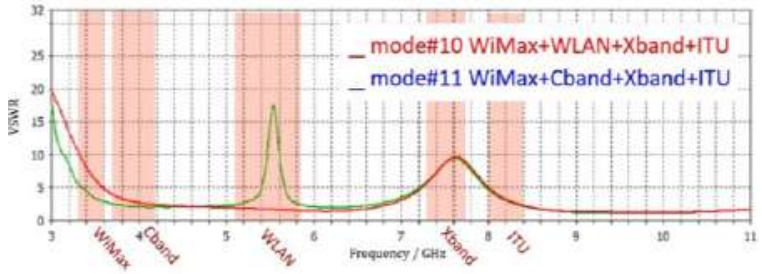

(e)

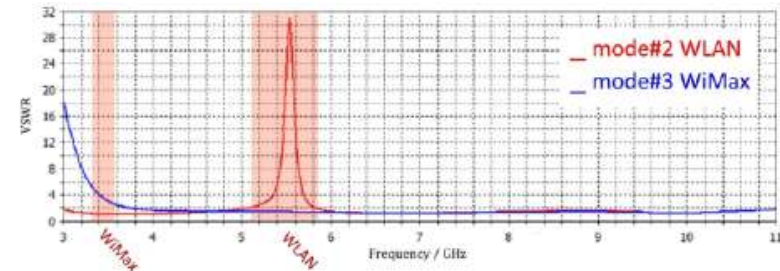

(b)

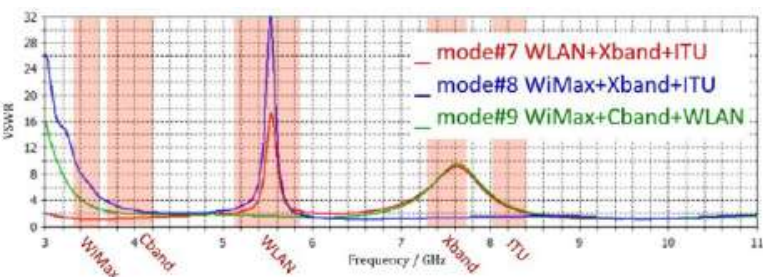

(d)

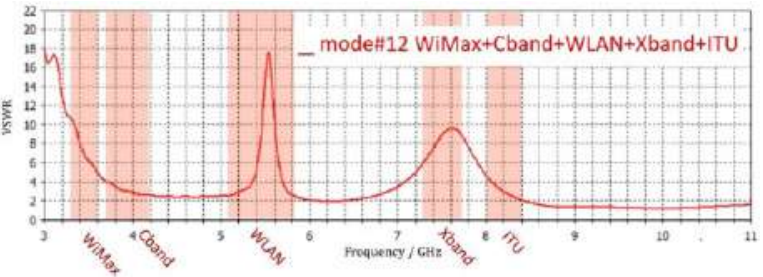

(f)

Figure 12. VSWR results: (a) UWB, (b) single-band rejection, (c) dual-band rejection, (d) triple-band rejection, (e) quad-band rejection and (f) penta-band rejection

Table 4. Comparison of the proposed design with recent related works in terms of size, number of switches, number of operation modes, rejected bands, and rejection states

\begin{tabular}{clccll}
\hline Ref. & Size $\left(\mathrm{mm}^{3}\right)$ & No. of diodes & No. of modes & Rejected bands & Rejection states \\
\hline$[1]$ & $40 \times 30 \times 0.78$ & 1 & 2 & WLAN & S \\
{$[2]$} & $35 \times 25 \times 0.78$ & 2 & 4 & WiMax, WLAN & S \\
{$[5]$} & $30 \times 22 \times 0.76$ & 2 & 2 & WLAN, ITU & S/D \\
{$[14]$} & $20 \times 20 \times 0.8$ & 2 & 4 & WiMax, WLAN & S/D \\
{$[20]$} & $28 \times 26 \times 0.8$ & 4 & 4 & WLAN, Xband & S/D \\
{$[21]$} & $38 \times 26 \times 1.5$ & 3 & 4 & WiMax, WLAN & S/D \\
{$[22]$} & $32 \times 36 \times 1.6$ & 3 & 4 & WiMax, WLAN & S \\
{$[23]$} & $19.5 \times 17 \times 1.6$ & 1 & 2 & WLAN & S/D/T \\
{$[24]$} & $25 \times 29 \times 1$ & 3 & 8 & WiMax,WLAN,ITU & S/D/T \\
{$[25]$} & $40 \times 38 \times 1.59$ & 4 & 7 & WiMax,WLAN,Xband & $\mathrm{S}$ \\
{$[26]$} & $30 \times 40 \times 0.78$ & 1 & 2 & WiMax & $\mathrm{S}$ \\
{$\left[26{ }^{*}\right.$} & $30 \times 40 \times 0.78$ & 1 & 2 & WLAN & S/D/T/Q/P \\
Proposed & $25 \times 25 \times 0.8$ & 4 & 12 & WiMax, Cband, WLAN, Xband, ITU \\
S: Single, D: Dual, T: Triple, Q: Quad, P: Penta , ${ }^{*}$ Two designs are presented in [26] & \multicolumn{7}{c}{}
\end{tabular}

\section{CONCLUSION}

This paper proposes an on-demand reconfigurable stop-band antenna that can serve underlay cognitive radio. This antenna is capable to work in twelve modes. These include UWB and reject C-band, WLAN, X-band and ITU in eleven modes. The design involves a wide slot antenna that is built over a Rogers RT/Duroid 5880 substrate. It achieves its reconfigurable band-notch characteristics via four PIN diodes that are layed across the slots of antenna's patch and ground plane. Surface current distribution figures are introduced to explain notch creation in those slots. S11, realized gain and VSWR results all certify the capability of this antenna to work as an UWB with band rejection characteristics. Comparing the proposed antenna to recent related works, this compact antenna has more bands to be rejected, more operation modes, and more rejection states. This achieved taking into consideration the efficient use of states resulting from the switching elements. So, this work looks promising as a flexible and feasible reconfigurable antenna that 
reduces the effect of interference in the targeted bands within UWB spectrum and thus enhances the quality of communication.

\section{ACKNOWLEDGEMENTS}

The authors are grateful to Mustansiriyah University, Al-Furat Al-Awsat Technical University and the University of Al-Qadisiyah for supporting the research facilities which helps to finish this work.

\section{REFERENCES}

[1] A. Alhegazi, Z. Zakaria, N. A. Shairi, A. Salleh, and S. Ahmed, "Compact UWB filtering-antenna with controllable WLAN band rejection using defected microstrip structure," Radioengineering, vol. 27, no. 1, pp. 110-117, 2018, doi: 10.13164/re.2018.0110.

[2] J. Li and Y. Sun, "Design of reconfigurable monopole antenna with switchable dual band-notches for UWB applications," Progress in Electromagnics Research C, vol. 96, pp. 97-107, 2019, doi: 10.2528/PIERC19081401.

[3] A. H. Majeed and K. H. Sayidmarie, "UWB elliptical patch monopole antenna with dual-band notched characteristics," International Journal of Electrical and Computer Engineering, vol. 9, no. 5, pp. 2088-8708, 2019, doi: 10.11591/ijece.v9i5.pp3591-3598.

[4] F. C. Commission, "Revision of part 15 of the commission's rules regarding ultra-wideband transmission systems," First Report and Order, pp. 02-48, Apr 2002.

[5] D. Yadav, M. P. Abegaonkar, S. K. Koul, V. Tiwari and D. Bhatnagar, "A monopole antenna with reconfigurable notched characteristics from WLAN-band notched UWB to ITU-band notched UWB antenna," in Optical and Wireless Technologies. Springer, Singapore, vol. 472, pp. 647-654, 2018, doi: 10.1007/978-981-10-7395-3_72.

[6] R. A. Abdulhasan, K. N. Ramli, R. Alias, L. Audah and A. R. O. Mumin, "Inverted diamond-shaped notched substrate and patch for high-frequency interference on ultra-wideband antenna," International Journal of Electrical and Computer Engineering, vol. 7, no. 6, pp. 2929-2935, 2017, doi: 10.11591/ijece.v7i6.pp2929-2935.

[7] M. Ojaroudi and N. Ojaroudi, "Ultra-wideband small rectangular slot antenna with variable band-stop function," in IEEE Transactions on Antennas and Propagation, vol. 62, no. 1, pp. 490-494, Jan. 2014, doi: 10.1109/TAP.2013.2287703.

[8] J. Kazim, A. Bibi, M. Rauf, M. Tariq and Owais, "A compact planar dual band-notched monopole antenna for UWB application," Microwave and Optical Technology Letters, vol. 56, no. 5, pp. 1095-1097, 2014, doi: 10.1002/mop.28270.

[9] Y. Ojaroudi, S. Ojaroudi, and N. Ojaroudi, "A novel 5.5/7.5 GHz dual band-stop antenna with modified ground plane for UWB communications," Wireless Personal Commununications, vol. 81, pp. 319-332, 2015, doi: 10.1007/s11277-014-2130-3.

[10] H. S. Mewara, J. K. Deegwal, and M. M. Sharma, "Design of Y-shaped immensely wideband printed monopole antenna with three notched bands," in Optical and Wireless Technologies. Springer, Singapore, vol. 546, pp. 233242, 2020, doi: 10.1007/978-981-13-6159-3_25.

[11] V. Dhasarathan, M. Sharma, M. Kapil, P. C. Vashist, S. K. Patel, and T. K. Nguyen, "Integrated Bluetooth/LTE2600 superwideband monopole antenna with triple notched (WiMAX/WLAN/DSS) band characteristics for UWB/X/Ku band wireless network applications," Wireless Networks, vol. 26, pp. 2845-2855, 2020, doi: 10.1007/s11276-019-02230-0.

[12] R. M. C. Cleetus and G. Josemin Bala, "Frequency reconfigurable antennas for cognitive radio applications: A review," International Journal of Electrical and Computer Engineering, vol. 9, no. 5, pp. 3542-3549, 2019, doi: 10.11591/ijece.v9i5.pp3542-3549.

[13] S. Ojaroudi, Y. Ojaroudi, and N. Ojaroudi, "Novel design of reconfigurable microstrip slot antenna with switchable band-notched characteristic," Microwave and Optical Technology Letters, vol. 57, no. 4, pp. 849-853, 2015, doi: 10.1002/mop.28980.

[14] M. B. Kakhki and P. Rezaei, "Reconfigurable microstrip slot antenna with DGS for UWB applications," International Jouranal of Microwave and Wireless Technologies, vol. 9, no. 7, pp. 1517-1522, 2017, $10.1017 / \mathrm{S} 1759078717000034$.

[15] M. M. Fakharian, P. Rezaei, and A. Azadi, "A Planar UWB bat-shaped monopole antenna with dual band-notched for WiMAX/WLAN/DSRC," Wireless Personal Communications, vol. 81, pp. 881-891, 2015, doi: 10.1007/s11277-014-2162-8.

[16] M. O. Al-Dwairi, "A planar UWB semicircular-shaped monopole antenna with quadruple band notch for WiMAX, ARN, WLAN, and X-band," International Journal of Electrical and Computer Engineering, vol. 10, no. 1, pp. 908918, 2020, doi: 10.11591/ijece.v10i1.pp908-918.

[17] I. D. S. Bahri, Z. Zakaria, N. A. Shairi, and N. Edward, "A novel UWB reconfigurable filtering antenna design with triple band-notched characteristics by using u-shaped coppers," International Journal of Electrical, Electronics and Computer Sience, vol. 14, no. 1, pp. 267-275, 2019, doi: 10.11591/ijeecs.v14.i1.pp267-275.

[18] T. D. Nguyen, D. H. Lee, and H. C. Park, "Design and analysis of compact printed triple band-notched UWB antenna," in IEEE Antennas and Wireless Propagation Letters, vol. 10, pp. 403-406, 2011, doi: 10.1109/LAWP.2011.2147270. 
[19] H. Yang, X. Xi, H. Hou, Y. Zhao, and Y. Yuan, "Design of reconfigurable monopole antenna with switchable dual band-notches for UWB applications," International Journal of Microwave and Wireless Technologies, vol. 10, no. 9, pp. 1065-1071, Nov 2018, doi: 10.1017/S175907871800096X.

[20] F. M. Alnahwi, A. A. Abdalhameed, H. L. Swadi, and A. S. Abdullah, "A compact wide-slot UWB antenna with reconfigurable and sharp dual-band notches for underlay cognitive radio applications," Turkish Journal of Electrical Engineering \& Computer Sciences, vol. 27, pp. 94-105, 2019, doi: 10.3906/elk-1803-63.

[21] G. Gao, B. Hu, L. He, S. Wang and C. Yang, "Investigation of a reconfigurable dual notched uwb antenna by conceptual circuit model and time-domain characteristics," Microwave and Optical Technology Letters, vol. 59, no. 6, pp. 1326-1332, 2017, doi: 10.1002/mop.30535.

[22] M. S. Alam and A. Abbosh, "Reconfigurable band-rejection antenna for ultra-wideband applications," IET Microwaves, Antennas \& Propagation, vol. 12, no. 2, pp. 195-202, 2017, doi: 10.1049/iet-map.2017.0442.

[23] V. Sharbati, P. Rezaei, and M. M. Fakharian, "Compact planar UWB antenna with enhanced bandwidth and switchable band-notch function for WLAN and DSRC," IETE Jouranal of Research., vol. 63, no. 6, pp. 805-812, 2017, doi: 10.1080/03772063.2017.1329634.

[24] C.-M. Luo, J.-S. Hong, M. Amin, and L. Zhong, "Compact UWB antenna with triple notched bands reconfigurable," 2016 IEEE International Conference on Microwave and Millimeter Wave Technology (ICMMT), 2016, pp. 746-748, doi: 10.1109/ICMMT.2016.7762429.

[25] A. S Kholapure and R. G. Karandikar, "UWB antenna with reconfigurable triple band notched characteristics for cognitive radio," ICTACT Journal on Communication Technology, vol.8, pp. 1553-1558, 2017, doi: 10.21917/ijct.2017.0229.

[26] N. F. Miswadi and M. T. Ali, "Design of Compact Reconfigurable UWB antenna with WiMAX and WLAN Band Rejection," Indonesian Journal of Electrical Engineering and Computer Science, vol. 17, no. 3, pp. 1427-1433, 2020, doi: 10.11591/ijeecs.v17.i3.pp1427-1433.

\section{BIOGRAPHIES OF AUTHORS}
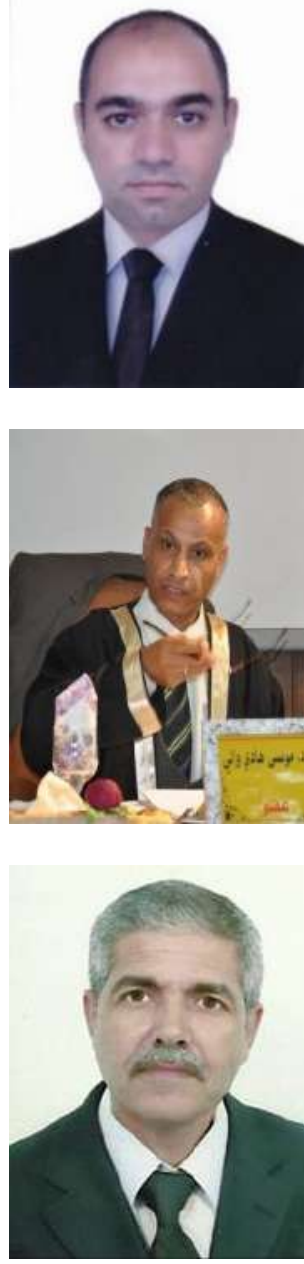

Laith Wajeeh Abdullah is currently a part time $\mathrm{PhD}$ student at the Department of Electrical Engineering, at Mustansiriyah University, Baghdad, Iraq. He is also an academic staff of the Communication Techniques Engineering Department at Al-Furat Al-Awsat Technical University, Najaf, Iraq. He received his B.Sc. degree in Electronics and Communication Engineering from the University of Baghdad, Baghdad, Iraq, in 1998 and his M.Sc. degree in 2002 from the University of Technology, Baghdad, Iraq. His research interests include reconfigurable antennas, cognitive radio, massive MIMO, wireless communications and IoT.

Musa Hadi Wali, Lecturer, Electronics and Communication Department, University of Qadisiyah, Al Diwaniyah, Iraq, is currently an academic staff of the Electronic and Communication Department at University of Qadisiyah, Al Diwaniyah, Iraq. He received his B.Sc. degree in Electrical Engineering from Mustansiriyah University, Baghdad, Iraq, in 1996, his M.Sc. degree in 2000 from the Mustansiriyah University, Baghdad, Iraq, and his PhD degree in 2016 from Basrah University, Basrah, Iraq. His research interests include wireless communications, and antenna.

Adheed Hassan Sallomi, received the B.Sc. degrees in Electrical Engineering from Mosul University, Iraq, in 1982, and received M.Sc., and Ph.D. degrees in Electrical Engineering from University of Technology, Baghdad, Iraq, in 2000, and 2007 respectively. $\mathrm{He}$ is currently working at Electrical Engineering Department of Mustansiriya University, Iraq. His research interests include radio waves propagation, channel modeling, smart antenna systems, and mobile communications. He has authored or co-authored over 30 scientific papers in the field of propagation, RF safety, and antennas. 